\title{
Acute poisoning due to Wright's Vaporizing Fluid
}

\author{
HeATHeR M. WiSEMAN* \\ M.Sc. \\ Winston M. L. TURNER $\dagger$ \\ M.D., F.R.C.P. \\ GLYN N. Volans* \\ M.D., M.R.C.P. \\ * National Poisons Information Service, Poisons Unit, Guy's Hospital, London, and
+ Burnley General Hospital, Burnley, Lancs
}

\begin{abstract}
Summary
A 3-year survey is reported of acute poisoning by Wright's Vaporizing Fluid which covered a change in formulation from $90 \%$ cresol to $10 \%$ chlorocresol. Of 160 children (average age 2.5 years) and 12 adults, $21.5 \%$ had moderate symptoms, $7.5 \%$ had severe symptoms and one child died. Where incidents involved the old formulation very few patients escaped without symptoms and over $50 \%$ of them had skin burns or moderate systemic symptoms. With the new formulation over $50 \%$ of the patients were asymptomatic and skin burns were uncommon. However there was no significant difference in the incidence of severe systemic symptoms between the formulations. The new formulation appears safer when small amounts of the fluid are ingested, but when larger amounts are involved it is potentially lethal. The case history of the fatal poisoning is presented.
\end{abstract}

\section{Introduction}

Wright's Vaporizing Fluid (Wright, Layman and Umney Ltd) is 'recommended for the relief of soreness and congestion of the upper respiratory tract'. It is administered by volatilization over a night-light in a purpose built 'vaporizer', producing a vapour which circulates throughout the room. The fluid itself is cresolic and the vapour, therefore, possesses a powerful 'antiseptic' smell. It is sold in 50-ml bottles from which $10-\mathrm{ml}$ portions are to be introduced into the vaporizer.

When used as instructed the vapour is apparently free from serious adverse effects, but if the unvolatilized fluid is ingested accidentally or deliberately, it is toxic and thus may result in acute poisoning. The product has always carried a clear warning label in red lettering, but nevertheless the National Poisons Information Service (NPIS) has received many enquiries for advice in the treatment of its ingestion. There is an impressive report in the literature of a case of a 12-month-old child who died apparently from absorption of cresol after the fluid had been spilt over his head (Green, 1975) but the J్ authors are unaware of any published reports where $\vec{P}$ the fluid was ingested. In January 1976 a prospective $\mathscr{\circ}$ survey of all such cases was begun. In December $\frac{\text { ? }}{2}$ 1976 the manufacturers informed the authors that $\rightarrow$ the formulation of the product had been changed $z$ from $90 \% \mathrm{v} / \mathrm{v}$ cresol to the potentially less toxic $10 \%$ $\mathrm{v} / \mathrm{v}$ chlorocresol. The survey has therefore extended $\textrm{ }$ over 3 years during which time an assessment of the $\overrightarrow{0}$ effects of this change has been attempted.

\section{Methods}

Details were recorded of the age of the patient, the amount of fluid ingested, the formulation involved, the signs and symptoms at the time of the $\frac{\circ}{\Phi}$ original telephone call. Further details of treatment $\stackrel{\varrho}{\rightarrow}$ and outcome were then sought by writing to the음 clinician concerned in each instance. Each case was classified according to the severity of symptoms and signs.

Type A: superficial skin burns only (on hands, 음 fingers, face and lips) from liquid having been spilt, but with no definite evidence of ingestion.

Type B: inflammation and a burning sensation in the mouth and throat, sometimes vomiting, abdomi-을 nal pain and dysphagia lasting some days.

Type C: severe poisoning often with blistering and 을 ulceration of the oral mucosa, oedema of the pharyn $x \frac{\text { O }}{2}$ and glottis, salivation and coughing, abdominal pain, vomiting, haematemesis, dyspnoea, pneu- $\sim \widetilde{N}$ monia, cough and collapse.

Type $\mathrm{C}$ cases may also show phenolic staining of the urine with evidence of liver and kidney damage.

\section{Results}

During the 3-year survey 311 cases were reported to the NPIS, 286 involving children. Type B symptoms were described in 54 and type $\mathrm{C}$ symptoms in 12. Follow-up information was received for $160 \stackrel{\mathrm{D}}{\mathrm{d}}$ 
children aged between 2 months and 9 years (average age, 2.5 years) and 12 adults aged between 14 and 75 years (average age, 34 years). Further discussion will be confined to those cases where follow-up information is available.

Among those followed-up, 31 children and 6 adults had type $B$ symptoms, while 11 children and 2 adults had type $C$ symptoms (Table 1 ). One child died, but all other cases recovered without long-term effects. Since January 1977 it has been possible to discover the formulation involved in just over $70 \%$ of the cases where follow-up information was received. Table 2 shows that in incidents with the old formulation very few patients escaped without symptoms and $>50 \%$ of them suffered skin burns or burns inside the mouth. With the new formulation, however, $>50 \%$ of the patients were asymptomatic and very few had skin burns (this difference is statistically significant, $\chi^{2}=17.27, P<0.001$ ). However, there was no significant difference in the incidence of more severe symptoms and the only death from this cause so far reported to the Service occurred in 1978 from the new formulation.

\section{Case history}

A previously healthy 2-year-old girl was admitted to Burnley General Hospital with the history that she had taken (or been given by another child) up to $40 \mathrm{ml}$ of the $10 \%$ chlorocresol formulation of Wright's Vaporizing Fluid $3 \mathrm{hr}$ earlier. On arrival she was semi-conscious, pale and cold, with tachypnoea and noisy breathing. The mouth and fauces were severely burned and some areas were sloughing. There was severe acidosis $\left(\mathrm{PO}_{2} 28, \mathrm{PCO}_{2} 16, \mathrm{pH} 7.05\right)$ and a marked leucocytosis (WBC $45 \times 10^{9} / 1$ ), with the systolic blood pressure only $90 \mathrm{mmHg}$. Treatment was started with oxygen and intravenous fluids to try to correct the acidosis. Antibiotics and hydrocortisone were given to prevent infection and reduce swelling of the airways. Intubation of the trachea was attempted but the severe sloughing in the oropharynx made this impossible. The acidosis and hypoxia could not be adequately controlled, her condition deteriorated, she had a short, generalized fit $23 \mathrm{hr}$ after admission and died $2 \mathrm{hr}$ later. Postmortem examination demonstrated sloughing of the upper respiratory and gastrointestinal tract. The bronchi were filled with green mucopus and there were petechial haemorrhages in the parietal pleura. The brain was oedematous and there was coning of the inferior surface of the cerebellum. Death was considered to be due to anoxia consequent upon the tissue damage to the upper respiratory tract.

\section{Discussion}

Cresol and chlorocresol are phenol derivatives which are caustic and exert their toxic effects directly on all cells by denaturation and precipitation of proteins. In small amounts they have salicylate-like stimulating effects on the respiratory centre, which causes respiratory alkalosis followed by acidosis due to uncompensated renal loss of base during the alkalosis, partly due to the acidic nature of the phenolic radical and partly from derangements in carbohydrate metabolism. They are excreted in the urine and after large doses renal damage is likely (Dreisbach, 1977).

Treatment is essentially supportive. After spillage, the skin should be washed well with water for up to $15 \mathrm{~min}$ followed by repeated application of castor

TABLE 1. Incidence of symptoms in cases of acute poisoning with Wright's Vaporizing Fluid reported to the NPIS between January 1976 to December 1978 (where adequate follow-up information was obtained)

\begin{tabular}{|c|c|c|c|c|c|}
\hline & without symptoms & with type A symptoms & $\begin{array}{l}(\%) \text { cases } \\
\text { with type B symptoms }\end{array}$ & with type $\mathrm{C}$ symptoms & $\begin{array}{l}\text { Total number } \\
\text { of cases }\end{array}$ \\
\hline $\begin{array}{l}\text { Children } \\
\text { Adults }\end{array}$ & $\begin{array}{r}64 \\
3\end{array}$ & $\begin{array}{r}54 \\
1\end{array}$ & $\begin{array}{r}31 \\
6\end{array}$ & $\begin{array}{c}11^{*} \\
2\end{array}$ & $\begin{array}{r}160 \\
12\end{array}$ \\
\hline Total & $67(38)$ & $55(31)$ & $37(21 \cdot 5)$ & $13(7 \cdot 5)$ & 172 \\
\hline
\end{tabular}

* Includes one death.

TABLE 2. Formulation of Wright's Vaporizing Fluid involved in cases reported to NPIS between January 1977 to December 1978 (where adequate follow-up information was obtained)

\begin{tabular}{|c|c|c|c|c|c|}
\hline \multirow[b]{2}{*}{ Formulation } & \multirow[b]{2}{*}{ none } & \multicolumn{2}{|c|}{ Symptoms } & \multirow[b]{2}{*}{ type $\mathrm{C}$} & \multirow[b]{2}{*}{ Tota } \\
\hline & & type $\mathbf{A}$ & type B & & \\
\hline $\begin{array}{l}\text { Old: } 90 \% \text { cresol } \\
\text { New: } 10 \% \text { chlorocresol } \\
\text { Not known }\end{array}$ & $\begin{array}{r}8 \\
28 \\
14\end{array}$ & $\begin{array}{r}18 \\
4 \\
12\end{array}$ & $\begin{array}{r}11 \\
10 \\
8\end{array}$ & $\begin{array}{l}6 \\
3 * \\
1\end{array}$ & $\begin{array}{l}43 \\
45 \\
35\end{array}$ \\
\hline Total & 50 & 34 & 29 & 10 & 123 \\
\hline
\end{tabular}

* Includes one death. 
oil. After ingestion, emesis and lavage are contraindicated because of the risk of further oesophageal damage and aspiration into the lungs. A milky drink, activated charcoal or castor oil may help to reduce absorption and should be followed, if possible, by a mild purge (e.g. sodium sulphate). In the more severe cases respiration is of paramount concern. Oxygen should be given, whilst intravenous fluids are adjusted to correct the metabolic imbalance and to maintain renal function. Antibiotics and hydrocortisone may help to prevent stricture formation. Diazepam is the anticonvulsant of choice. Dialysis would be indicated in the event of severe acute renal failure, but the authors have no experience of cases where this was used.

It is not possible to correlate the severity of poisoning with amount of fluid ingested because it is usually difficult to estimate how much a small child has swallowed. However, from the experience of cases reported to the authors, not only during the survey but before it (during 1963 to 197528 serious cases were reported to them), amounts as small as $5 \mathrm{ml}$ to $10 \mathrm{ml}$ of the old formulation can cause severe illness in a small child. Such a small amount of the new formulation seems to cause little more than soreness in the mouth and throat, but it is still potentially lethal if swallowed in larger amounts.

When the new formulation was introduced in December 1976, the manufacturers attempted to recall unsold bottles of the old formulation. This exercise was not entirely successful and since the authors are aware of at least 13 incidents involving the old formulation that occurred between January and June 1979 they are concerned that this materia is still available both in the home and in a smale number of shops.

Since it appears that even the new formulation can :cause serious problems it is pertinent to considers measures which may help to prevent further cases ofo acute poisoning. These might include child-resistantocontainers (CRC), improved labelling, unit dosen packaging and altered formulation. When they dis- $\widehat{\Omega}_{0}$ cussed this report with the manufacturers the authorso were informed that a CRC would be introduced? forthwith and that the other measures, although $P$ much more complex, would be considered. In the meantime it is hoped that this paper will bring the problem to the attention of doctors and pharmacists and that awareness of the problem will help to prevent further accidents. The authors will continueir to monitor any further cases reported to them and hope to include a study of the urinary excretion of cresol and chlorocresol.

\section{Acknowledgments}

We would like to thank those doctors who supplied us $\vec{z}$ with details of the cases under their care and Mr M. H. James of LRC Products on behalf of the manufacturers, for his constructive approach to the prevention of this cause of acute $\supset$ poisoning.

\section{References}

DreisbaCH, R.H. (1977) A Handbook of Poisoning, 9th Ed. Lange Medical Publication, Los Altos, California.

GrEeN, M.A. (1975) A household remedy misused-fatalō cresol poisoning following cutaneous absorption (a case report). Medicine, Science and the Law, 15, 65. 